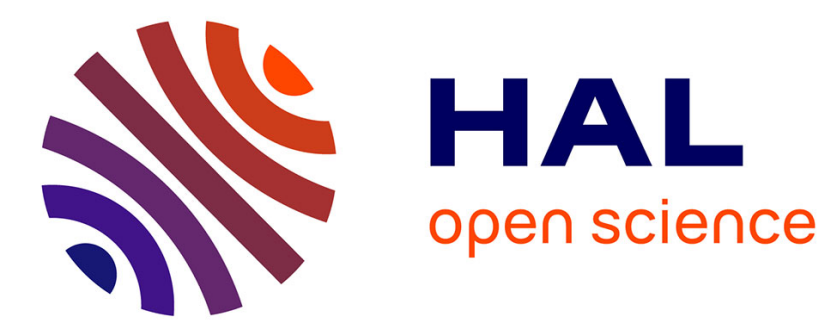

\title{
Nonlinear Mechanism of the Exchange Rate Pass-Through: Does Business Cycle Matter?
}

Nidhaleddine Ben Cheikh

\section{To cite this version:}

Nidhaleddine Ben Cheikh. Nonlinear Mechanism of the Exchange Rate Pass-Through: Does Business

Cycle Matter?. 2012. halshs-00731502

\section{HAL Id: halshs-00731502 \\ https://shs.hal.science/halshs-00731502}

Preprint submitted on 12 Sep 2012

HAL is a multi-disciplinary open access archive for the deposit and dissemination of scientific research documents, whether they are published or not. The documents may come from teaching and research institutions in France or abroad, or from public or private research centers.
L'archive ouverte pluridisciplinaire HAL, est destinée au dépôt et à la diffusion de documents scientifiques de niveau recherche, publiés ou non, émanant des établissements d'enseignement et de recherche français ou étrangers, des laboratoires publics ou privés. 


\title{
Nonlinear Mechanism of the Exchange Rate Pass-Through: Does Business Cycle Matter?
}

\author{
Nidhaleddine Ben Cheikh * \\ CREM, University of Rennes 1, 7 Place Hoche, 35065, Rennes Cedex, France
}

\begin{abstract}
This paper examines the presence of nonlinear mechanism in the exchange rate pass-through (ERPT) to CPI inflation for 12 euro area (EA) countries. Using logistic smooth transition models, we explore the existence of nonlinearity with respect to economic activity along the business cycle. Our results provide a strong evidence of nonlinearity in 6 out of 12 EA countries with significant differences in the degree of ERPT between the periods of expansion and recession. However, we find no clear direction in this regime-dependence of pass-through to business cycle. In some countries, ERPT is higher during expansions than in recessions; however, in other countries, this result is reversed. These cross-country differences in the nonlinear mechanism of pass-through would have important implications for the design of monetary policy and the control of inflation in the EA context.
\end{abstract}

J.E.L classification: $\mathrm{C} 22, \mathrm{E} 31, \mathrm{~F} 31$

Keywords: Exchange Rate Pass-Through, Inflation, Smooth Transition Regression

*Tel.: +332232335 48. E-mail address: nbeneche@univ-rennes1.fr. 


\section{Introduction}

The issue of nonlinearities is one of the burgeoning topics in the literature of Exchange Rate Pass-Through (ERPT) ${ }^{1}$. In spite of its policy relevance, studies dealing with nonlinearities in pass-through mechanism are still relatively scarce. Mainly, the existing empirical literature on this area has put forth the role of exchange rate in generating nonlinearities. In one hand, nonlinearity is tested with respect to the direction of currency movements, i.e. whether ERPT responds asymmetrically to appreciations and depreciations episodes. In the other hand, some studies emphasize on the role of the size of exchange rate changes as a potential source of nonlinearities, i.e. if ERPT would be higher for large exchange rate changes than for small ones. However, as pointed by Marazzi et al. (2005), previous studies provide mixed results with no clear support for the existence of important nonlinearities.

If the existing literature is not conclusive, there are two important caveats should be noted in this regard. First, ERPT is not depending exclusively on exchange rate changes, there are various factors, including macroeconomic variables, which might influence the pass-through mechanisms. Thus, other sources of nonlinearities may exist. For example, Correa \& Minella (2006) found that ERPT respond to business cycle in a nonlinear way. Second, an appropriate econometric tool is required. In fact, several empirical studies has experimented a standard linear models augmented with interactive dummy variables in order to capture nonlinear or asymmetric behavior in pass-through. These added interactive terms would account for appreciation or depreciation episodes as well as for some specific events such as unusual exchange rate developments ${ }^{2}$. For example, Coughlin $\&$ Pollard (2004) use threshold dummy variables to distinguish between large and small exchange rate changes, in order to capture possible asymmetries in ERPT. The authors choose an arbitrary threshold value for all US industries equal to $3 \%$. A large exchange rate change is defined as being $3 \%$ and above, while a small change is below 3\%. However, for more accuracy, the threshold level must be estimated from the data instead of using an arbitrary value. An alternative methodology is to estimate a nonlinear regime-switching model where a grid search is used to select the appropriate threshold. Amongst this class of models, two popular nonlinear models can be mentioned. First, the so-called threshold regression model where the transition across regimes is abrupt ${ }^{3}$. Second, the smooth transition regression

\footnotetext{
${ }^{1}$ The exchange rate pass-through is defined as the degree to which exchange rate changes are reflected in the domestic prices. This latter may involve different prices index, especially, import prices and consumer prices.

${ }^{2}$ See Yang (2007).

${ }^{3}$ The univariate case is known as the threshold autoregressive (TAR) model.
} 
(STR) model with the transition between states is rather smooth ${ }^{4}$. In our paper, we propose to use the second type of regime-switching model, namely a class of STR models, in order to test the presence of nonlinear mechanism in the ERPT.

To the best of our knowledge, there are only two studies that using a smooth nonlinear regression in the context of pass-through. In one hand, Shintani et al. (2009) estimated the ERPT to US domestic prices with respect to inflation regime. They find that the period of low ERPT would be associated with the low inflation environment. In the other hand, Nogueira Jr. \& Leon-Ledesma (2008) examine the possibility of nonlinear pass-through for a set of "Inflation Target" countries. They found that ERPT responds nonlinearly to several macroeconomic factors, including economic activity ${ }^{5}$.

Therefore, our paper aims at contributing to fill the gap in empirical evidence on the nonlinearities in ERPT. We focus on "consumer-price pass-through", i.e. the sensitivity of consumer prices to exchange rate changes. Our study is close to Nogueira Jr. \& Leon-Ledesma (2008) who examined the role of business cycle in generating asymmetry by implementing a logistic STR model. The correlation between economic activity and the degree of pass-through has put forth by Goldfajn \& Werlang (2000). The authors report an asymmetric reaction of the ERPT over the business cycle, i.e. the transmission of exchange rate changes would be higher when the economy is booming than in periods of recession. Thus, in our paper, we raise the question of whether the business cycle constituting a source of nonlinearity in ERPT. Unlike Nogueira Jr. \& Leon-Ledesma (2008), we are interested in the euro area (EA) case, since we expect that the different macroeconomic developments experienced by the monetary union members would generate a nonlinear mechanism in ERPT. To our knowledge, there is no other study has applied a nonlinear STR estimation approach in this context.

The remainder of the paper is structured as follows: Section 2 discusses the analytical framework that underlies the nonlinear mechanism of pass-through. In section 3, the empirical specification is presented. Section 4 gives the main empirical results and Section 6 concludes.

\footnotetext{
${ }^{4}$ The univariate case is known as smooth transition autoregressive (STAR) model.

${ }^{5}$ Herzberg et al. (2003) analyzed the ERPT into UK import prices using a STR model but did not find any evidence of nonlinearity.
} 


\section{Analytical framework}

Let us consider a foreign firm that exports its product $i$ to an importing country. Under monopolistic competition, the first-order conditions for exporter profit maximization, with price $P_{i}$ set in importing country currency, yield the following expression:

$$
P_{i}=E \mu_{i} W_{i}^{*}
$$

Where $E$ is the exchange rate measured in units of the importer currency per unit of the foreign currency, $\mu_{i}$ is the markup of price over marginal cost $W_{i}^{*}$ of foreign producer. The markup is defined as $\mu_{i} \equiv \eta_{i} /\left(1-\eta_{i}\right)$, where $\eta_{i}$ is the price elasticity of demand for the good $i$ in the importing country. As in Bailliu \& Fujii (2004), $\mu_{i}$ is assumed to depend essentially on demand pressures in the destination market: $\mu_{i}=\mu(Y)$, with $Y$ is the income (expenditures) level in the importing country.

The log-linear form of equation (1) gives the standard ERPT regression traditionally tested throughout the exchange rate pass-through literature (see Goldberg $\&$ Knetter (1997) $)^{6}$ :

$$
p_{t}=\alpha+\beta e_{t}+\psi y_{t}+\delta w_{t}^{*}+\varepsilon_{t},
$$

From equation (2), the ERPT coefficient is given by coefficient $\beta$ and is expected to be bounded between 0 and 1 . If $\beta=1$, exporter markup will not respond to fluctuations of the exchange rates, so price is set in foreign country currency (producer-currency pricing, $\mathrm{PCP}$ ) and pass-through is complete. If $\beta=0$, the ERPT is zero since foreign firm decide not to vary the prices in the destination country currency and absorb the fluctuations within the markup. This is a purely local-currency pricing (LCP).

In the other hand, pricing strategies of firms depend not solely on demand conditions in the market. One can think that foreign firm may adjust price after exchange rate movements with respect to some macroeconomic factors. For instance, inflation environment, as argued by Taylor (2000), could influence the extent of ERPT. In a stable inflation environment ERPT would be lower than in higher inflation episodes. Another important determinant of the ERPT mechanism is the business cycle. This latter might affect the transmission of exchange rate changes in a nonlinear way. In fact, firms are more willing to pass-through cost increases such as those coming from the exchange rate when the economy is

\footnotetext{
${ }^{6}$ For simplicity, the good superscript $i$ is dropped and time index $t$ is added. Lower cases variables denote logarithms.
} 
growing faster, rather than when it is in a recession. Then, it is expectable that ERPT would be higher in periods of prosperity than in periods of slowdown. Empirically, this intuition was confirmed by Goldfajn \& Werlang (2000) in a panel of 71 countries. The authors found that depreciations have a higher pass-through to prices in periods of expansion. Using Phillips curve threshold model, Correa \& Minella (2006) gave a support of a nonlinear dynamic behavior of ERPT with respect to business cycle in Brazil. Similarly, in a nonlinear smooth transition framework, Nogueira Jr. \& Leon-Ledesma (2008) find that pass-through responds nonlinearly to the output growth in 3 out of 6 Inflation Target countries. Thus, in our paper, following the mentioned studies, we consider the economic activity as the main driving factor of the nonlinearity in pass-through mechanism. We consider that pricing strategy of foreign firms to depend on importer's macroeconomic environment - mainly the economic activity - in a nonlinear framework. Then, we consider $\kappa(M)$ as a function including those macroeconomic determinants such as business cycle. This macroeconomic dependence is seen as a firms' strategic decision on how much to translate exchange rate changes given different macroeconomic scenarios in the importing country. Taking into account these factors, we can re-write foreign firm markup as follow:

$$
\mu_{i}=\mu\left(Y, E^{\kappa(M)}\right),
$$

According to equation (1) and (3), ERPT equation in logarithms becomes:

$$
\begin{aligned}
p_{t} & =\alpha+\beta e_{t}+\psi y_{t}+\kappa(M) e_{t}+\delta w_{t}^{*}+\varepsilon_{t} \\
& =\alpha+[\beta+\kappa(M)] e_{t}+\psi y_{t}+\delta w_{t}^{*}+\varepsilon_{t},
\end{aligned}
$$

According to the function $\kappa(M)$, there is an indirect channel of pass-through which depends on the macroeconomic environment. Therefore, we assume that economic activity, as an important "macro-determinant" of ERPT, affect firm's markup in a nonlinear way. We consequently consider that there is some threshold $M^{*}$ which provides two extreme macroeconomic regimes, namely high and low economic activity.

$$
\kappa(M)= \begin{cases}0 & \text { for } M \leq M^{*} \\ \phi & \text { for } M \geq M^{*}\end{cases}
$$


According to (4) and (5), the degree of pass-through would be different and depends on whether the economic activity is above or below a threshold level. If economic activity in the importing country is below some threshold $\left(M \leq M^{*}\right)$, i.e. in periods of economic slowdown (or recession), then ERPT would be equal to $\beta$. If economic activity in the importing country is above a threshold, $\left(M>M^{*}\right)$, i.e. during economic expansion, then ERPT becomes $(\beta+\phi)$. The equations (4) and (5) have the advantage to describe this changing behavior in pass-through in a nonlinear fashion. Thus, we expect the extent of pass-through would be different with respect to the business cycle, that is, the transmission of exchange rate changes would be higher when economy is booming than during economic slowdown. Finally, it should be noted that the transition from one regime to the other is assumed to be smooth.

\section{Empirical approach}

\subsection{Smooth transition regression models}

To capture nonlinearity in the exchange rate transmission, we use a class of smooth transition regression (STR) models as a tool. A STR model is defined as follows:

$$
y_{t}=\beta^{\prime} \mathbf{z}_{t}+\phi^{\prime} \mathbf{z}_{t} G\left(s_{t} ; \gamma, c\right)+u_{t}
$$

Where $u_{t} \sim \operatorname{iid}\left(0, \sigma^{2}\right), \mathbf{z}_{t}=\left(\mathbf{w}_{t}^{\prime}, \mathbf{x}_{t}^{\prime}\right)^{\prime}$ is an $((m+1) \times 1)$ vector of explanatory variables with $\mathbf{w}_{t}^{\prime}=\left(y_{t-1}, \ldots, y_{t-d}\right)^{\prime}$ and $\mathbf{x}_{t}^{\prime}=\left(x_{1 t}, \ldots, x_{k t}\right)^{\prime} . \beta=\left(\beta_{0}, \beta_{1}, \ldots, \beta_{m}\right)^{\prime}$ and $\phi=\left(\phi_{0}, \phi_{1}, \ldots, \phi_{m}\right)^{\prime}$ are the parameter vectors of the linear and the nonlinear part, respectively. $G\left(s_{t} ; \gamma, c\right)$ is the transition function bounded between 0 and 1 , and depends upon the transition variable $s_{t}$, the slope parameter $\gamma$ and the location parameter $c .^{7}$ The transition variable $s_{t}$ is an element of $\mathbf{z}_{t}$, and then is assumed to be a lagged endogenous variable $\left(s_{t}=y_{t-d}\right)$ or an exogenous variable $\left(s_{t}=x_{k t}\right)$. A popular choice for the transition function is the logistic specification that is given by ${ }^{8}$ :

$$
G\left(s_{t} ; \gamma, c\right)=\left[1+\exp \left\{-\gamma\left(s_{t}-c\right)\right\}\right]^{-1}
$$

\footnotetext{
${ }^{7}$ The parameter $\gamma$ is also called the speed of transition which determines the smoothness of the switching from one regime to the other.

${ }^{8} \mathrm{An}$ alternative transition function which is often used in the literature is the exponential specification: $G\left(s_{t} ; \gamma, c\right)=1-\exp \left\{-\gamma\left(s_{t}-c\right)^{2}\right\}$.
} 
Where the parameter $c$ can be interpreted as the threshold level between two extremes regimes: $G\left(s_{t} ; \gamma, c\right)=0$ is called the lower regime and $G\left(s_{t} ; \gamma, c\right)=1$ is the upper regime. Equations (6) and (7) jointly define the logistic STR (LSTR) model. In this latter, the nonlinear coefficients would take different values depending on whether the transition variable is below or above the threshold. Thus, the parameters $\left[\beta+\phi G\left(s_{t} ; \gamma, c\right)\right]$ changes monotonically as a function of $s_{t}$ from $\phi$ to $(\beta+\phi)$. In this sense, as $\left(s_{t}-c\right) \rightarrow-\infty, G\left(s_{t} ; \gamma, c\right) \rightarrow 0$ and coefficients correspond to $\beta$; if $\left(s_{t}-c\right) \rightarrow+\infty$, then $G\left(s_{t} ; \gamma, c\right) \rightarrow 1$ and coefficients become $(\beta+\phi)$; and if $s_{t}=c$, then $G\left(s_{t} ; \gamma, c\right)=1 / 2$ and coefficients will be $(\beta+\phi / 2) .{ }^{9}$ LSTR model is pertinent in describing asymmetric dynamic behavior between negative or positive deviations of the transition variable $s_{t}$ from the threshold level $c$. As mentioned in the STR literature (see e.g. van Dijk et al. (2002)), when modeling business cycle, LSTR can describe processes whose dynamic properties are different in expansions from what they are in recessions. For example, if the transition variable $s_{t}$ is a business cycle indicator (such as output growth), and if $c \simeq 0$, the model distinguishes between periods of positive and negative growth, that is, between expansions and contractions.

As discussed in Teräsvirta (1994), the modelling strategy of STR models is consisting of three stages: specification, estimation, and evaluation. The first stage consists in testing for nonlinearity and choosing the appropriate threshold variable $s_{t}$ and the most suitable form of the transition function, i.e. logistic or exponential specification ${ }^{10}$. In the second stage, the parameters of the STR model are estimated by nonlinear least squares (NLS) estimation technique which provides estimators that are consistent and asymptotically normal. Finding good starting values is crucial in this procedure. Thus, STR literature suggests to construct a grid search for estimating $\gamma$ and $c$. The values for the grid search for $\gamma$ were set between 0 and 100 for increments of 1 , whereas $c$ was estimated for all the ranked values of the transition variable $s_{t}$. For each value of $\gamma$ and $c$ the residual sum of squares is computed. The values that correspond to the minimum of that sum are taken as starting values into the NLS procedure. This procedure increases the precision of the estimates and ensures faster convergence of the NLS algorithm ${ }^{11}$. In the final stage, evaluation stage, the quality of the estimated STR model should be checked against misspecification as in the case of linear models. Several misspecification tests are used in the STR literature, such as LM test of no error autocorrelation,

\footnotetext{
${ }^{9}$ It should be noted that LSTR model would follow the same pattern as the threshold model described in the theoretical model (equation (5)), assuming a smooth adjustment across regimes.

${ }^{10}$ More details for linearity tests in Appendix A.

${ }^{11}$ It should also be noted that when constructing the grid, $\gamma$ is not a scale-free. The transition parameter $\gamma$ is therefore standardized by dividing it by the sample standard deviation of the transition variable $s_{t}$.
} 
LM-type test of no ARCH and Jarque-Bera normality test. Eitrheim \& Teräsvirta (1996) suggested two additional LM-type misspecification tests: an LM test of no remaining nonlinearity and LM-type test of parameter constancy.

\subsection{Model specification and data}

In our empirical analysis, we define LSTR pass-through equation which is derived from the theoretical model (4). It consists of an extension of Bailliu \& Fujii (2004) pass-through model to nonlinear case. Then, the equation to estimate has the following form:

$$
\begin{aligned}
\pi_{t}=\alpha+\sum_{j=0}^{N} \beta_{j} \Delta e_{t-j}+ & \left(\sum_{j=0}^{N} \phi_{j} \Delta e_{t-j}\right) G\left(s_{t} ; \gamma, c\right) \\
& +\sum_{j=0}^{N} \psi_{j} \Delta y_{t-j}+\sum_{j=0}^{N} \delta_{j} \Delta w_{t-j}^{*}+\varepsilon_{t},
\end{aligned}
$$

Where $\pi_{t}$ is the CPI inflation rate, $\Delta e_{t}$ is the rate of depreciation of the nominal effective exchange rate, $\Delta y_{t}$ is the output growth, used to capture changes in domestic demand conditions, and $\Delta w_{t}^{*}$ is the changes in foreign producer cost. $G\left(s_{t} ; \gamma, c\right)$ is the logistic transition function driving the nonlinear dynamic. A measure of the economic activity is considered as a transition variable $s_{t}$ in the LSTR pass-through equation (see below section 4 for more details). According to (8), the degree of ERPT is given by the following time-varying coefficients:

$$
E R P T=\beta_{0}+\phi_{0} G\left(s_{t} ; \gamma, c\right)
$$

The ERPT coefficient would take different values depending on whether the transition variable $s_{t}$ is below or above the threshold value ${ }^{12}$. If $\left(s_{t}-c\right) \rightarrow-\infty$, i.e. the economic activity is below the threshold, pass-through coefficient is equal to: $\mathrm{ERPT}=\beta_{0}$. This corresponds to the pass-through elasticity during low activity regime (when $G\left(s_{t} ; \gamma, c\right)=0$ ). However, if $\left(s_{t}-c\right) \rightarrow+\infty$, i.e. the economic activity is above the threshold, then pass-through coefficient becomes: ERPT $=\beta_{0}+\phi_{0}$. This latter corresponds to the degree of pass-through during high activity regime (when $G\left(s_{t} ; \gamma, c\right)=1$ ).

\footnotetext{
${ }^{12} \mathrm{We}$ can compute the long-run ERPT as the sum of linear and nonlinear parts of the model: $\sum_{j=0}^{N} \beta_{j}+\sum_{j=0}^{N} \phi_{j} G\left(s_{t} ; \gamma, c\right)$. However, this definition of long-run pass-through was severely criticized by de Bandt et al. (2008). The authors point out that this measure is very sensitive to the number of lags introduced in the model, leading to inaccurate long-run effect.
} 
The LSTR pass-through equation (8) is estimated for 12 EA countries (Austria, Belgium, Germany, Spain, Finland, France, Greece, Ireland, Italy, Luxembourg, Netherlands and Portugal), using quarterly data spanning the period 1975:1 to 2010:4. All the data we use are taken from the OECD's Economic Outlook database, except for exchange rate series which are obtained from International Financial Statistics (IFS) of the International Monetary Fund (IMF). Inflation rates series represents the quarterly change in consumer prices index (CPI). Output growth is constructed using the rate of growth of the real GDP. The nominal exchange rate is defined as domestic currency units per unit of foreign currencies, which implies that an increase represents a depreciation for home country. Finally, to capture changes in foreign costs, we follow Bailliu \& Fujii (2004) by constructing an exporter partners' cost proxy. In logarithms, this latter is measured as follow: $w_{t}^{*} \equiv q_{t}+u l c_{t}-e_{t}$, where $q_{t}$ is the unit labor cost (ULC) based real effective exchange rate, $u l c_{t}$ is the ULC in domestic country and $e_{t}$ the nominal effective exchange rate ${ }^{13}$. To determine the lag length of the variables, we follow van Dijk et al. (2002) by adopting a general-to-specific approach to select the final specification. We start with a model with maximum lag length of $N=4$, and then dropping sequentially the lagged variables for which the $t$-statistic of the corresponding parameter is less than 1.0 in absolute value.

\section{Main Empirical Results}

In this section we raise the question of whether the degree of ERPT is affected by the business cycle in a nonlinear way. The sparse empirical evidence on this issue has put forth a positive relationship between economic activity and the transmission of exchange rate. Intuitively, in periods where the economy is booming, firms are more willing to pass-through cost increases such as those coming from the exchange rate, meaning that ERPT would be greater in periods of prosperity than in periods of slowdown. In accordance with this argument, García \& Restrepo (2001) has explained that the lower ERPT in Chile in the 1990s is due, in part, to the positive dependence of pass-through to economic activity. According to the authors, the negative output gap during this period has offset the inflationary impact of exchange rate depreciation by reducing margins. To the best of our knowledge, only the study of Nogueira Jr. \& Leon-Ledesma (2008) that used

\footnotetext{
${ }^{13}$ We have checked the possibility of cointegrating relationship among our variables in ERPT equation (4). Individual series in level are non-stationary but do not appear to be cointegrated according to Engle-Granger tests. As a result, log differences of the variables are used in the estimation the STR pass-through equation as shown in equation (8). Augmented Dickey Fuller (ADF) tests suggest that variables in differences are appropriately described as stationary series.
} 
STR model to capture nonlinearity in ERPT with respect to the business cycle. The authors investigated the presence of nonlinearities in a sample of 6 developed and developing Inflation Target countries. Our paper, unlike Nogueira Jr. \& Leon-Ledesma (2008), deals with the euro area (EA) case, since we expect that the different macroeconomic developments experienced by the monetary union members would generate a nonlinear mechanism in ERPT.

In our empirical specification, the economic activity is considered as the driving factor of the nonlinear dynamic. As a proxy for the economic activity along the business cycle, we consider the rate of growth of the real GDP ${ }^{14}$. Thus, the lagged real GDP growth is considered as the transition variable $\left(s_{t}=\Delta y_{t-j}\right)$ in the STR model. When its values exceeding an estimated threshold, these can be interpreted as periods of expansion. While, when values are below the threshold, these are periods of economic slowdown or recession. The choice of the adequate lagged real GDP growth as a transition variable by means of linearity tests is reported in Table 2 in Appendix A. The linearity tests are conducted for each lagged output growth $\Delta y_{t-j}$ with $j=1,2,3,4$. According to linearity tests, there is a strong evidence of presence of nonlinearities in 9 out of 12 EA countries (except for France, Ireland and Luxembourg $)^{15}$. Once linearity has been rejected, the sequence of nested null hypotheses is conducted in order to choose the adequate transition function (logistic or exponential) ${ }^{16}$. As explained before, the economic intuition must be also considered in our choice of the relevant STR specification. According to van Dijk et al. (2002), LSTR models are more appropriate in describing processes whose dynamic properties are different in expansions from what they are in recessions. Effectively, in accordance with theoretical priors (section 2), the ERPT may be different whether economic activity is above or below a given threshold. In other words, the exchange rate changes would have a higher pass-through when the economy is growing faster than when the output growth is below the threshold. Thus, given these features, the LSTR model is preferred to ESTR. Estimation results from the LSTR pass-through equation (8) are summarized in Table 1. They concern only EA countries rejecting the null of linearity (9 out of 12 EA countries). In addition to the estimated threshold level and the speed of transition, we report ERPT coefficients for the two extremes regimes, i.e. low and high activity regimes $\left(G\left(s_{t} ; \gamma, c\right)=0\right.$ and $G\left(s_{t} ; \gamma, c\right)=1$, respectively) as defined in equation $(9)^{17}$.

\footnotetext{
${ }^{14}$ In their studies, Goldfajn \& Werlang (2000) and Correa \& Minella (2006) used the output gap as proxy for the economic activity. However, as explained by Nogueira Jr. \& Leon-Ledesma (2008), the use of an ad hoc detrending processes like the output gap might eliminate valuable information from the data.

${ }^{15}$ See the first row of Table 2 in Appendix A.

${ }^{16}$ See the second row until the last in Table 2 in Appendix A.

${ }^{17}$ Full results of NLS estimates of our LSTR models are presented in the Table 3 in Appendix C.
} 
Table 1: Estimated ERPT elasticities from LSTR model

\begin{tabular}{lccccccccc}
\hline \hline & Austria & Belgium & Germany & Spain & Finland & Greece & Italy & Netherlands & Portugal \\
\hline Transition variable $\left(s_{t}\right)$ & $\Delta y_{t-1}$ & $\Delta y_{t-3}$ & $\Delta y_{t-4}$ & $\Delta y_{t-3}$ & $\Delta y_{t-2}$ & $\Delta y_{t-2}$ & $\Delta y_{t-1}$ & $\Delta y_{t-4}$ & $\Delta y_{t-3}$ \\
\hline Threshold $(c)$ & 0,040 & 0,003 & 0,010 & 0,006 & 0,029 & 0,021 & 0,017 & 0,007 & 0,013 \\
& $(0,000)$ & $(0,000)$ & $(0,079)$ & $(0,509)$ & $(0,000)$ & $(0,009)$ & $(0,000)$ & $(0,000)$ & $(0,000)$ \\
Speed of transition $(\gamma)$ & 24,444 & 20,760 & 3,304 & 26,210 & 3,740 & 4,585 & 3,944 & 8,959 & 26,378 \\
& $(0,651)$ & $(0,168)$ & $(0,162)$ & $(0,000)$ & $(0,193)$ & $(0,202)$ & $(0,003)$ & $(0,265)$ & $(0,311)$ \\
\hline Low activity regime : $G=0$ & & & & & & & & & \\
$E R T$ & 0,044 & 0,105 & 0,024 & 0,049 & 0,010 & 0,112 & 0,044 & 0,043 & 0,093 \\
& $(0,001)$ & $(0,000)$ & $(0,269)$ & $(0,129)$ & $(0,708)$ & $(0,001)$ & $(0,000)$ & $(0,025)$ & $(0,021)$ \\
\hline High activity regime: $G=1$ & & & & & & & & & \\
$E R P T$ & 0,222 & 0,071 & 0,136 & 0,163 & 0,080 & 0,006 & 0,073 & 0,032 & 0,126 \\
& $(0,012)$ & $(0,000)$ & $(0,005)$ & $(0,000)$ & $(0,007)$ & $(0,936)$ & $(0,736)$ & $(0,075)$ & $(0,162)$ \\
\hline$R^{2}$ & 0,735 & 0,772 & 0,695 & 0,845 & 0,790 & 0,870 & 0,954 & 0,737 \\
SSR & 0,812 & 0,681 & 0,818 & 0,729 & 0,790 & 0,859 & 0,413 & 0,826 & 0,793 \\
$p J B$ & 0,466 & 0,364 & 0,081 & 0,000 & 0,108 & 0,005 & 0,000 & 0,462 & 0,000 \\
$p L M_{A R(4)}$ & 0.1898 & 0,968 & 0,429 & 0,393 & 0,015 & 0,057 & 0,543 & 0,691 & 0,121 \\
$p L M_{A R C H(4)}$ & 0,446 & 0,996 & 0,058 & 0,093 & 0,228 & 0,316 & 0,000 & 0,917 & 0,019 \\
$p L M_{C}$ & 0,193 & 0,176 & 0,625 & 0,010 & 0,642 & 0,088 & 0,539 & 0,660 & 0,241 \\
$p L M_{R N L}$ & 0,410 & 0,851 & 0,943 & 0,618 & 0,787 & 0,164 & 0,572 & 0,506 & 0,730 \\
\hline \hline
\end{tabular}

Note: Table reports elasticities of exchange rate pass-through into CPI inflation from LSTR models. Numbers in parentheses are $p$-values of estimates. $R^{2}$ denotes the coefficient of determination and $S S R_{\text {ratio }}$ is the ratio of sum of squared residuals between LSTR model and the linear specification. The following rows corresponds to the misspecification tests: $p J B$ is the ip to for 
We compute sum of squared residuals ratio $\left(S S R_{\text {ratio }}\right)$ between LSTR model and the linear specification which suggests a better fit for the nonlinear model. We also check the quality of the estimated LSTR models by conducting several misspecification tests. In most of cases, the selected LSTR models pass the main diagnostic tests, i.e. no error autocorrelation, no conditional heteroscedasticity, parameters constancy and non remaining nonlinearity. According to Table 1, threshold values of real GDP growth are significant and vary significantly across EA countries, ranging from $0.3 \%$ in Belgium to $4 \%$ in Austria ${ }^{18}$. Concerning pass-through estimates, there are 6 out of 9 EA countries showing significant nonlinear ERPT with respect to business cycle. In other words, pass-through elasticity is significantly different between low and high activity regimes in 6 EA countries. Also, we denote that the extent of pass-through depends positively on economic activity for 4 out of 6 EA countries. For these countries, the exchange rate transmission to CPI inflation is significantly greater when output growth is above some threshold. For instance, the pass-through coefficient in Germany is $0.02 \%$ not significantly different from zero when GDP growth is below $1 \%$, i.e. during economic slowdown. However, when German economy is growing faster - above the threshold of $1 \%$ - ERPT elasticity increase to about $0.13 \%$. Also, we have plotted both the estimated transition functions and the ERPT as a function of the transition variable lagged real GDP (see Figure 1 in Appendix B). Plots reveal the regime-dependence of ERPT to business cycle. The positive connection between the degree of the ERPT and real GDP growth is quite clear for 4 out of 6 EA countries. These results are consistent with the existing empirical literature dealing with the issue of nonlinearity. In their LSTR model, Nogueira Jr. \& LeonLedesma (2008) found the same positive link between pass-through and economic activity. This is true for 3 out of their 6 Inflation Target countries. Similarly, in a Phillips curve threshold framework, Correa \& Minella (2006) suggest that when the output gap is above a certain threshold, ERPT becomes higher in Brazil. Moreover, Goldfajn \& Werlang (2000) provide an evidence of asymmetric behavior of ERPT over the business cycle in a panel of 71 countries. The authors found that depreciations have a higher pass-through to prices during prosperity periods.

Besides, we found a significant negative link between ERPT and output growth in Belgium and Netherlands, that is, when real GDP growth is below some threshold, the extent of ERPT becomes higher (see Figure 1 in Appendix B). In fact, this is not surprising if low or negative output growth is seen as a period of economic slump or macroeconomic instability. If foreign producers expect less stable conditions in importing country, they may shift away from local-currency

\footnotetext{
${ }^{18}$ According to van Dijk et al. (2002) estimates of speed of transition $(\gamma)$ may appear to be insignificant. This should not be interpreted as evidence of weak nonlinearity.
} 
pricing strategy ( $L C P$ strategy), leaving their prices affected by exchange rate changes. As a result, ERPT would be higher in periods of macroeconomic distress than in prosperity episodes. To give further insight on this plausible negative relationship, we plot time-varying ERPT coefficients over the period 1975-2010 (see Figure 2 in Appendix B). On the same graphs, we also report lagged real GDP growth and the estimated threshold level. According to Figure 2, the extent of passthrough was higher in both Belgium and Netherlands during periods of contraction or recession. For example, we find an increasing rate of ERPT over the European Monetary System (EMS) crisis (1992-1993) and in the 2008 financial crisis. Due to macroeconomic instability episodes, it is more likely that foreign firms tend to modify pricing strategy by choosing the exporter's currency invoicing ( $P C P$ strategy) in stead of the importer's currency pricing ( $L C P$ strategy). Therefore, it is not really surprising that pass-through would be greater in Belgium and Netherlands during these periods.

In all, our results reveal no clear direction in this regime-dependence of ERPT to business cycle. In some countries, ERPT is higher during periods of expansion than in periods of recession; however, in other countries, this result is reversed. The responsiveness of CPI inflation to exchange rate changes along the business cycle is different between these two groups of EA countries. So, we can conclude that the nonlinear mechanism of ERPT is an heterogeneous phenomenon across monetary union members. This outcome would have important implications for the design of monetary policy and the expectation of inflation in the euro area. Monetary policy during turbulent exchange rate periods should factor in the nonlinear mechanism of ERPT over the business cycle and how it affects inflation dynamics.

\section{Conclusion}

In this study, we investigate for possible nonlinear mechanism in the exchange rate pass-through (ERPT) to CPI inflation for 12 euro area (EA) countries. This exercise is conducted using the family of smooth transition regression models as a tool. In spite of its policy relevance, studies dealing with the nonlinearities in pass-through mechanisms are still relatively scarce. Therefore, our paper aims at contributing to fill the gap in empirical evidence on the nonlinearities in ERPT. Especially, we explore the existence of nonlinearities with respect to the business cycle. Using quarterly data spanning from 1975 to 2010, we find strong evidence that passthrough respond nonlinearly to economic activity in 6 out of 12 EA countries. In other words, the extent of pass-through is found to be different between the periods of expansion and recession in half of EA countries. However, we find no clear direction in this regime-dependence of pass-through to business cycle. In some 
countries, ERPT is higher during expansions than in recessions; however, in other countries, this result is reversed. These cross-country differences in the nonlinear mechanism of pass-through would have important implications for the design of monetary policy and the control of inflation in the monetary union.

\section{Appendix A. Linearity test}

In order to derive a linearity test, Teräsvirta $(1994,1998)$ suggested to approximate the logistic function (7) in (6) by a third-order Taylor expansion around the null hypothesis $\gamma=0$. The resulting test has power against both the LSTR and ESTR models. Assuming that the transition variable $s_{t}$ is an element in $\mathbf{z}_{t}$ and let $\mathbf{z}_{t}=$ $\left(1, \tilde{\mathbf{z}}_{t}^{\prime}\right)^{\prime}$, where $\tilde{\mathbf{z}}_{t}^{\prime}$ is an $(m \times 1)$. Taylor approximation yields the following auxiliary regression:

$$
y_{t}=\alpha_{0}^{\prime} \mathbf{z}_{t}+\sum_{j=1}^{3} \alpha_{j}^{\prime} \widetilde{\mathbf{z}}_{t} s_{t}^{j}+u_{t}^{*}, \quad t=1, \ldots, T,
$$

Where $u_{t}^{*}=u_{t}+R_{3}\left(\gamma, c, s_{t}\right) \theta^{\prime} \mathbf{z}_{t}$, with $R_{3}\left(\gamma, c, s_{t}\right)$ the residual of Taylor expansion. The null hypothesis of linearity is $H_{0}: \alpha_{1}=\alpha_{2}=\alpha_{3}=0$. van Dijk et al. (2002) suggest the use of $F$-versions of Lagrange Multiplier (LM) test statistic, which has an approximate $F$-distribution with $3 m$ and $T-4 m-1$ degrees of freedom under $H_{0}$. Linearity tests are executed for each of the candidates potential transition variables, which are lagged output growth in our case. Once linearity has been rejected, one has to choose whether logistic or exponential function should be specified. The choice between these two types of models is based on the auxiliary regression (10). Teräsvirta $(1994,1998)$ suggested that this choice can be based on testing the following sequence of nested null hypotheses:

1. Test $H_{04}: \alpha_{3}=0$

2. Test $H_{03}: \alpha_{2}=0 \mid \alpha_{3}=0$

3. Test $H_{02}: \alpha_{1}=0 \mid \alpha_{2}=\alpha_{3}=0$

According to Teräsvirta (1994), the decision rule is the following: if the test of $H_{03}$ yields the strongest rejection measured in the $p$-value, choose the ESTR model. Otherwise, select the LSTR model. Tables (2) provides the $p$-values of the $F$ version of the LM test with the different lags for the output growth. In the first row, we report the test of the null hypothesis of linearity against the alternative of STR nonlinear model. The following rows in each table show the sequence of null hypotheses for choosing the LSTR or the ESTR model. 
Table 2: Linearity tests against STR model with $s_{t}=\Delta y_{t-j}$

\begin{tabular}{|c|c|c|c|c|c|c|c|c|c|c|c|c|}
\hline & \multicolumn{4}{|l|}{ Austria } & \multicolumn{4}{|c|}{ Belgium } & \multicolumn{4}{|c|}{ Germany } \\
\hline & $\Delta y_{t-1}$ & $\Delta y_{t-2}$ & $\Delta y_{t-3}$ & $\Delta y_{t-4}$ & $\Delta y_{t-1}$ & $\Delta y_{t-2}$ & $\Delta y_{t-3}$ & $\Delta y_{t-4}$ & $\Delta y_{t-1}$ & $\Delta y_{t-2}$ & $\Delta y_{t-3}$ & $\Delta y_{t-4}$ \\
\hline$H_{0}$ & 0,183 & 0,933 & 0,009 & 0,035 & 0,010 & 0,837 & 0,040 & 0,349 & 0,373 & 0,032 & 0,011 & 0,042 \\
\hline$H_{04}$ & 0,056 & 0,986 & 0,016 & 0,054 & 0,128 & 0,666 & 0,025 & 0,373 & 0,162 & 0,278 & 0,023 & 0,212 \\
\hline$H_{03}$ & 0,991 & 0,100 & 0,155 & 0,351 & 0,001 & 0,818 & 0,679 & 0,176 & 0,602 & 0,007 & 0,543 & 0,082 \\
\hline$H_{01}$ & 0,519 & 0,823 & 0,281 & 0,102 & 0,083 & 0,813 & 0,388 & 0,829 & 0,581 & 0,475 & 0,023 & 0,137 \\
\hline \multirow{3}{*}{ Specification } & Linear & Linear & LSTR & LSTR & ESTR & Linear & LSTR & Linear & Linear & ESTR & LSTR & ESTR \\
\hline & Spain & & & & Finlanc & & & & France & & & \\
\hline & $\Delta y_{t-1}$ & $\Delta y_{t-2}$ & $\Delta y_{t-3}$ & $\Delta y_{t-4}$ & $\Delta y_{t-1}$ & $\Delta y_{t-2}$ & $\Delta y_{t-3}$ & $\Delta y_{t-4}$ & $\Delta y_{t-1}$ & $\Delta y_{t-2}$ & $\Delta y_{t-3}$ & $\Delta y_{t-4}$ \\
\hline$H_{0}$ & 0,339 & 0,453 & 0,044 & 0,473 & 0,319 & 0,039 & 0,039 & 0,037 & 0,178 & 0,593 & 0,136 & 0,144 \\
\hline$H_{04}$ & 0,292 & 0,811 & 0,531 & 0,634 & 0,701 & 0,030 & 0,035 & 0,139 & 0,180 & 0,684 & 0,001 & 0,195 \\
\hline$H_{03}$ & 0,322 & 0,078 & 0,007 & 0,146 & 0,221 & 0,412 & 0,696 & 0,809 & 0,486 & 0,308 & 0,800 & 0,589 \\
\hline$H_{01}$ & 0,649 & 0,534 & 0,165 & 0,691 & 0,201 & 0,169 & 0,053 & 0,005 & 0,199 & 0,576 & 0,019 & 0,085 \\
\hline \multirow[t]{3}{*}{ Specification } & Linear & Linear & ESTR & Linear & Linear & LSTR & LSTR & LSTR & Linear & Linear & Linear & Linear \\
\hline & Greece & & & & Ireland & & & & Italy & & & \\
\hline & $\Delta y_{t-1}$ & $\Delta y_{t-2}$ & $\Delta y_{t-3}$ & $\Delta y_{t-4}$ & $\Delta y_{t-1}$ & $\Delta y_{t-2}$ & $\Delta y_{t-3}$ & $\Delta y_{t-4}$ & $\Delta y_{t-1}$ & $\Delta y_{t-2}$ & $\Delta y_{t-3}$ & $\Delta y_{t-4}$ \\
\hline$H_{0}$ & 0,001 & 0,000 & 0,000 & 0,012 & 0,373 & 0,304 & 0,947 & 0,403 & 0,000 & 0,000 & 0,000 & 0,080 \\
\hline$H_{04}$ & 0,798 & 0,000 & 0,047 & 0,139 & 0,857 & 0,894 & 0,921 & 0,036 & 0,056 & 0,102 & 0,280 & 0,267 \\
\hline$H_{03}$ & 0,000 & 0,017 & 0,000 & 0,018 & 0,175 & 0,050 & 0,789 & 0,971 & 0,000 & 0,000 & 0,000 & 0,416 \\
\hline$H_{01}$ & 0,093 & 0,248 & 0,064 & 0,176 & 0,095 & 0,166 & 0,571 & 0,878 & 0,000 & 0,005 & 0,000 & 0,032 \\
\hline \multirow[t]{3}{*}{ Specification } & ESTR & LSTR & ESTR & ESTR & Linear & Linear & Linear & Linear & ESTR & ESTR & ESTR & Linear \\
\hline & \multicolumn{4}{|c|}{ Luxembourg } & \multicolumn{4}{|c|}{ Netherlands } & \multicolumn{4}{|c|}{ Portugal } \\
\hline & $\Delta y_{t-1}$ & $\Delta y_{t-2}$ & $\Delta y_{t-3}$ & $\Delta y_{t-4}$ & $\Delta y_{t-1}$ & $\Delta y_{t-2}$ & $\Delta y_{t-3}$ & $\Delta y_{t-4}$ & $\Delta y_{t-1}$ & $\Delta y_{t-2}$ & $\Delta y_{t-3}$ & $\Delta y_{t-4}$ \\
\hline$H_{0}$ & 0,785 & 0,473 & 0,978 & 0,360 & 0,017 & 0,006 & 0,047 & 0,025 & 0,669 & 0,025 & 0,033 & 0,003 \\
\hline$H_{04}$ & 0,964 & 0,510 & 0,837 & 0,716 & 0,009 & 0,004 & 0,148 & 0,066 & 0,897 & 0,282 & 0,192 & 0,373 \\
\hline$H_{03}$ & 0,852 & 0,537 & 0,867 & 0,090 & 0,249 & 0,260 & 0,380 & 0,045 & 0,674 & 0,055 & 0,031 & 0,000 \\
\hline$H_{01}$ & 0,070 & 0,295 & 0,884 & 0,512 & 0,322 & 0,171 & 0,037 & 0,410 & 0,038 & 0,017 & 0,200 & 0,229 \\
\hline Specification & Linear & Linear & Linear & Linear & LSTR & LSTR & LSTR & ESTR & Linear & LSTR & ESTR & ESTR \\
\hline
\end{tabular}

Note: The numbers are $p$-values of $F$ versions of the LM linearity tests. First row shows the test of linearity against the alternative of STR nonlinearity. The second row until the forth are the $p$-values of the sequential test for choosing the adequate transition function. The decision rule is the following: if the test of $H_{03}$ yields the strongest rejection of null hypothesis 


\section{Appendix B. Plots from LSTR pass-through equation}

Figure 1: Estimated transition functions and ERPT as a function of past output growth

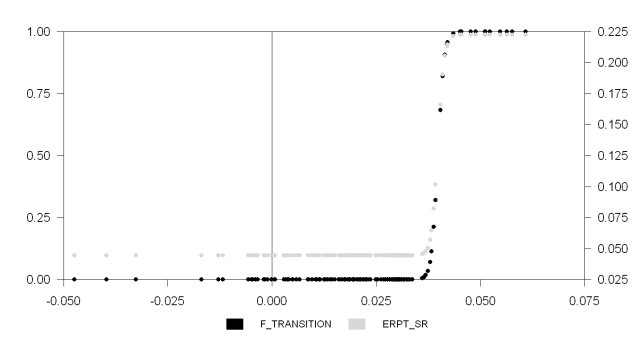

Austria

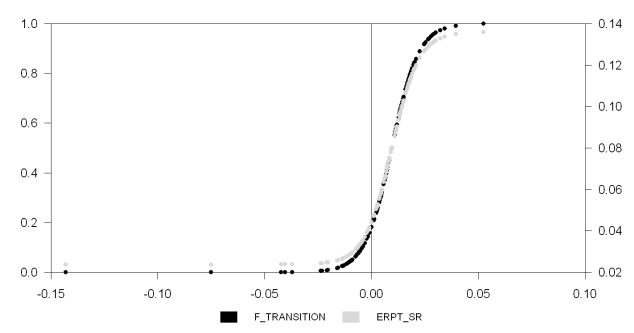

Germany

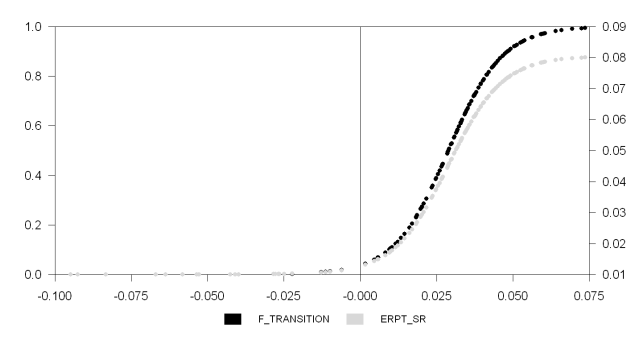

Finland

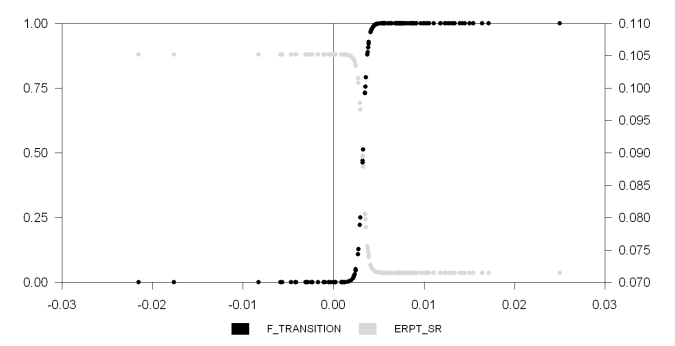

Belgium

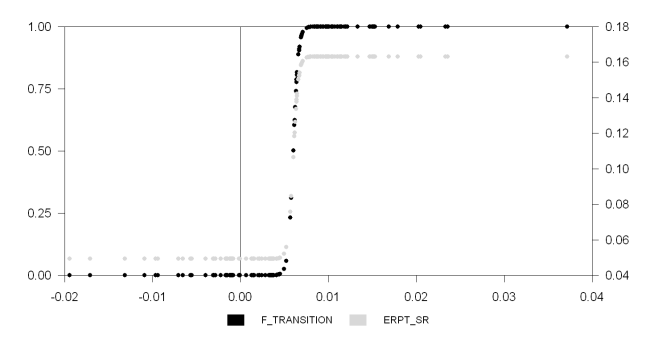

Spain

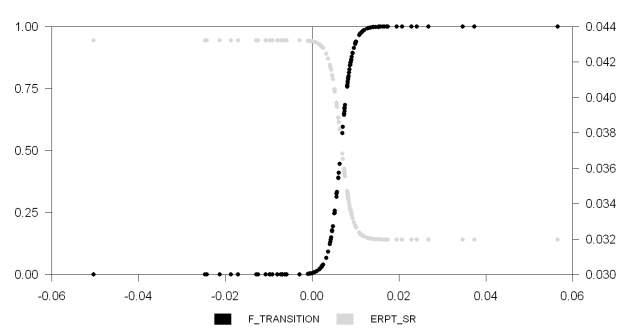

Netherlands

Note: Estimated transition functions and ERPT as a function of past output growth. Results are from LSTR model with $s_{t}=\Delta y_{t-i}$. 
Figure 2: Time-varying ERPT and past output growth

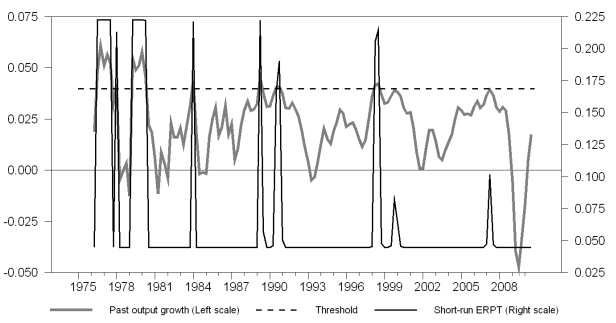

Austria

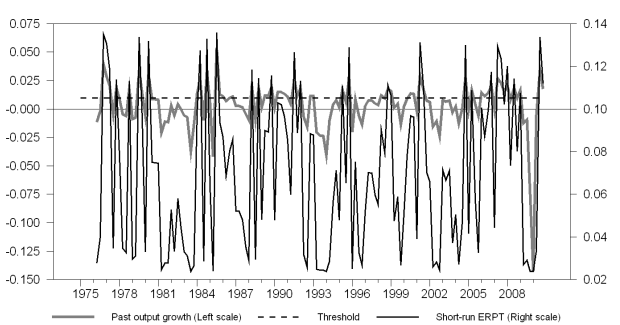

Germany

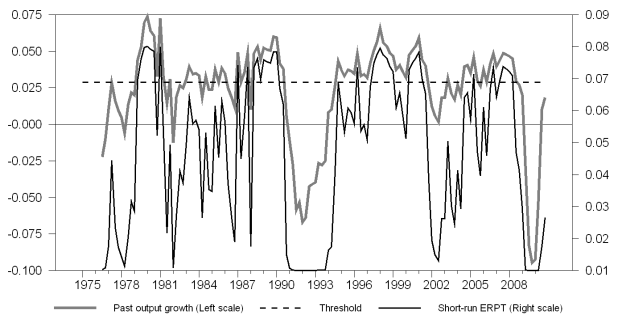

Finland

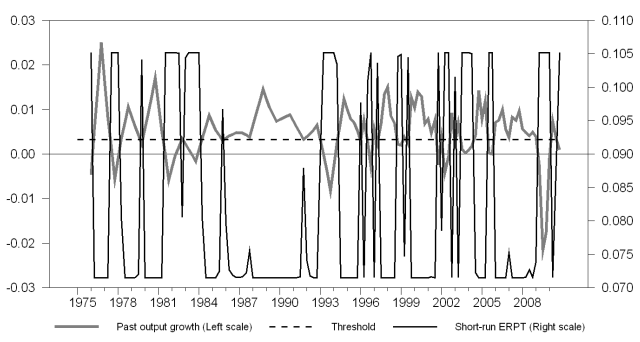

Belgium

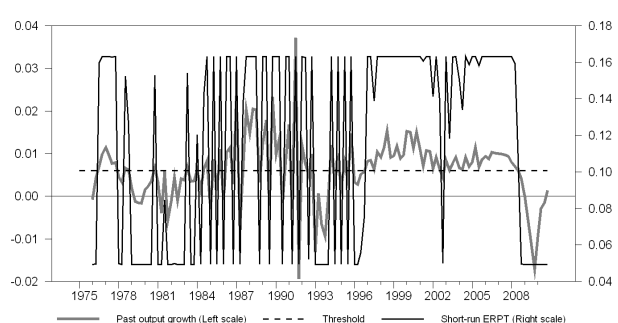

Spain

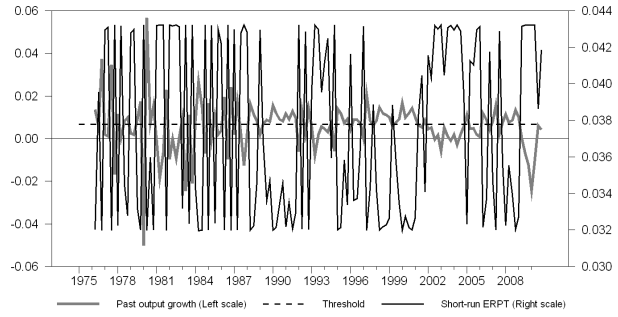

Netherlands

Note: Time-varying ERPT and past output growth between 1975-2010. Results are from LSTR model with $s_{t}=\Delta y_{t-i}$. 


\section{Appendix C. Full Results from STR pass-through models}

Table 3: Estimation results from LSTR model

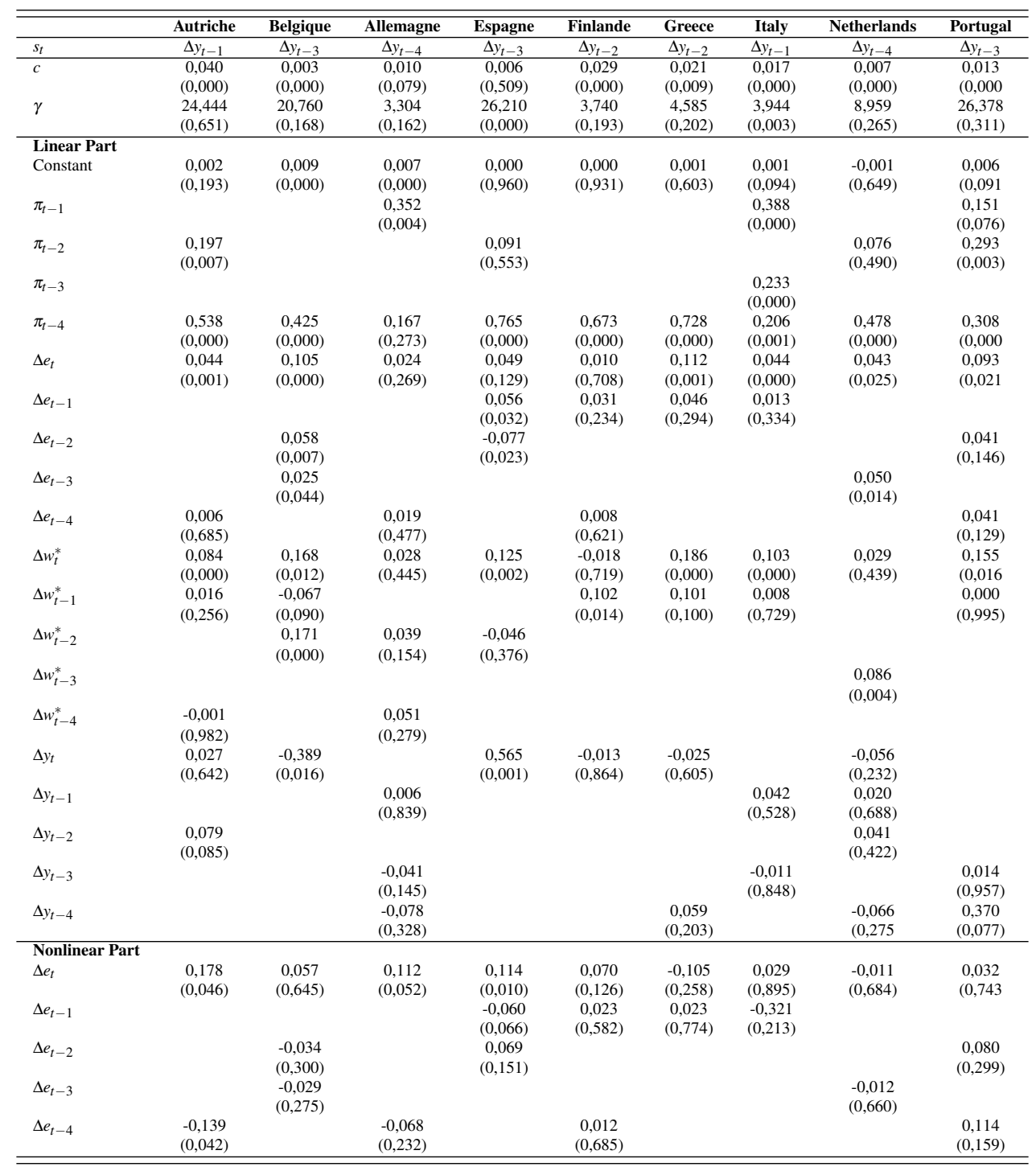

Key: Table reports estimates of LSTR pass-through equation. Numbers in parentheses are p-values. 


\section{References}

Bailliu, J. \& Fujii, E. [2004]. "Exchange Rate Pass-Through and the Inflation Environment in Industrialized Countries: An Empirical Investigation”. Working Paper No. 2004-21, Bank of Canada.

Correa, A. \& Minella, A. [2006]. "Nonlinear mechanisms of exchange rate passthrough: a Phillips curve model with threshold for Brazil". Working Paper No. 122, Central Bank of Brazil.

Coughlin, C. C. \& Pollard, P. S. [2004]. "Size Matters: Asymmetric Exchange Rate Pass- Through at the Industrial Level". Working Paper No. 2003-029C, Federal Reserve Bank of St. Louis.

de Bandt, O., Banerjee, A. \& Kozluk, T. [2008]. "Measuring long run exchange rate pass-through". Economics: The Open-Access, Open-Assessment E-Journal, 2 (2008-6).

Eitrheim, Ø. \& Teräsvirta, T. [1996]. "Testing the adequacy of smooth transition autoregressive models". Journal of Econometrics, Vol. 74, pp. 59-76.

García, J., C. \& Restrepo, E., J. [2001]. "Price inflation and Exchange rate passthrough in Chile". Working Paper No. 128, Central bank of Chile.

Goldberg, P.K. \& Knetter, M. [1997]. “Goods Prices and Exchange Rates: What Have We Learned?” Journal of Economic Literature, 35, pp. 1243-72.

Goldfajn, I. \& Werlang, S.R.C. [2000]. "The Pass-through from Depreciation to Inflation: A Panel Study”. Working Paper No. 423, Banco Central Do Brasil.

Herzberg, V., Kapetanios, G. \& Price, S. [2003]. "Import prices and exchange rate pass-through: Theory and evidence from the United Kingdom." Working Paper No. 182, Bank of England.

Marazzi, M., Sheets, N., Vigfusson, R., Faust, J., Gagnon, J., Marquez, J., Martin, R., Reeve, T. \& Rogers, John [2005]. "Exchange Rate Pass-through to U.S. Import Prices: some New Evidence”. International Finance Discussion Paper No. 832, Board of Governors of the Federal Reserve System.

Nogueira Jr., R. P. \& Leon-Ledesma, M. [2008]. "Exchange Rate Pass-Through Into Inflation: The Role of Asymmetries and NonLinearities". Studies in Economics No. 0801, Department of Economics, University of Kent. 
Shintani, M., A., Terada-Hagiwara \& Y., Tomoyoshi [2009]. "Exchange Rate PassThrough and Inflation: A Nonlinear Time Series Analysis". Working paper, Department of Economics, Vanderbilt University.

Taylor, J. [2000]. "Low Inflation, Pass-Through and the Pricing Power of Firms". European Economic Review, 44, pp. 1389-1408.

Teräsvirta, T. [1994]. "Specification, estimation and evaluation of smooth transition autoregressive models". Journal of the American Statistical Association, 89, pp. 208-218.

Teräsvirta, T. [1998]. "Modelling Economic Relationship with Smooth Transition Regressions”. In D.E.A. Giles \& A. Ullah (Eds.), Handbook of Applied Economic Statistics (Marcel Dekker, New York).

van Dijk, D., Teräsvirta, T. \& Franses, P. [2002]. "Smooth Transition Autoregressive Models: A Survey of Recent Developments". Econometric Reviews, 21, pp. 1-47. 